\title{
'Candidatus Borrelia texasensis', from the American dog tick Dermacentor variabilis
}

Correspondence

James H. Oliver, Jr Joliver@GeorgiaSouthern.edu
Relapsing fever is a medically important borreliosis caused by different species of relapsing fever borreliae. It is found in North America, Europe and Africa and is transmitted by various species of Ornithodoros and Argas ticks or lice (Barbour \& Hayes, 1986). Two major groups of Borrelia are the Borrelia burgdorferi sensu lato species complex and the relapsing fever borreliae. To date, 11 genospecies in the B. burgdorferi complex and more than 20 species of relapsing fever borreliae have been reported. Only three of the 11 genospecies of B. burgdorferi sensu lato are proven agents

Published online ahead of print on 22 October 2004 as DOI 10.1099/ ijs.0.02864-0.

The GenBank/EMBL/DDBJ accession numbers for the 16S rRNA gene and flaB gene sequences of TXW-1 are AF467976 and AF264901.

A scanning electron micrograph of a cell of TXW-1 is available as supplementary material in IJSEM Online. of Lyme disease in humans. Borrelia recurrentis, the agent of louse-borne relapsing fever, and several species of tickborne spirochaetes are included among the relapsing fever borreliae.

Specific relationships are often found among borreliae and vector species. Although several different genospecies of B. burgdorferi sensu lato can be transmitted by several species of ticks, the ticks are closely related and most are in the Ixodes ricinus species complex. The relapsing fever borreliae and their tick vectors have an even stricter relationship. Some borreliae are reported to be transmitted by a single tick species (Kelly, 1976; Schwan \& Piesman, 2002); however, this tick-spirochaete specificity theory needs reinvestigation using molecular analysis and experimental transmission experiments.

Most relapsing fever borreliae are transmitted by softbodied ticks (Ornithodoros or Argas species), but there are 
exceptions. For example, $B$. recurrentis is transmitted by the human biting louse, Pediculus humanus, and Borrelia theileri is vectored by the hard-bodied ticks Rhipicephalus (several species) and Boophilus microplus (Anderson \& Magnarelli, 1993). Moreover, 'Borrelia lonestari' has been detected and cultured in the hard tick Amblyomma americanum from the US states of Texas, New Jersey, New York, Missouri and Georgia (Barbour et al., 1996; Varela et al., 2004), and a Borrelia species genetically close to Borrelia miyamotoi has been detected in Ixodes scapularis from Rhode Island, Connecticut, New York and New Jersey (Scoles et al., 2001). Also, a B. miyamotoi-like Borrelia species appears to be present in Ixodes ricinus ticks in Europe (Fraenkel et al., 2002). In Japan, B. miyamotoi is vectored by the closely related Ixodes persulcatus, which also is a vector of the Lyme borreliosis spirochaetes Borrelia garinii and Borrelia afzelii (Fukunaga \& Koreki, 1995).

The American tick-borne relapsing fever spirochaetes Borrelia hermsii, Borrelia parkeri and Borrelia turicatae were successfully cultured 30 years ago (Kelly, 1971, 1976, 1984). Although investigation of Lyme borreliosis stimulated improvements in the cultivation of some of the most notable borreliae, such as B. recurrentis and Borrelia duttonii (Cutler et al., 2000), some species remain uncultivated, such as the borreliae from New England transmitted by Ixodes scapularis (Scoles et al., 2001).

The aim of this study was to characterize the genetic and phenotypic features of isolate TXW-1. By using different genotyping and phenotyping methods, we were able to classify this isolate and clarify its taxonomic status. Our results indicate that TXW-1 represents an undescribed species in the relapsing fever borreliae complex. Although we were able to culture this spirochaete, we are currently unable to revive the frozen cultures and thus can not meet the requirements of the Bacteriological Code to deposit viable type material at two different culture collections. Therefore we propose that TXW-1 should be described as 'Candidatus Borrelia texasensis'.

TXW-1 was isolated in BSK-H medium (Sigma-Aldrich) in March 1998 from an adult male Dermacentor variabilis feeding on a coyote from Webb county, Texas. Cultures were incubated at $34^{\circ} \mathrm{C}$ for $1-2$ weeks until the cell density

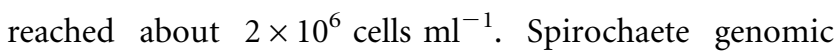
DNA was extracted by methods described previously (Zingg et al., 1993).

A $348 \mathrm{bp}$ fragment of the flagellin B gene (flaB) (for RFLP analysis) was amplified by using a pair of primers, FlaLS (5'-AACAGCTGAAGAGCTTGGAATG-3'; positions 438459) and FlaRS (5'-CTTTGATCACTTATCATTCTAATAGC-3'; 791-766) (Barbour et al., 1996). Another fragment of $\mathrm{flaB}$ (for sequence analysis) was amplified by using primers FlaLL (5'-ACATATTCAGATGCAGACAGAGGT$3^{\prime}$; 301-324) and FlaRL (5'-GCAATCATAGCCATTGCAGATTGT-3'; 942-965) (Barbour et al., 1996). A 1532 bp segment of the 16S rRNA gene ( $r r s$ ) was amplified by using a pair of primers $\mathrm{fD} 3$ (5'-AGAGTTTGATCCTGGCTTAG$\left.3^{\prime} ; 8-27\right)$ and UniB (5'-TACAAGGAGGTGATCCAGC-3'; 1539-1522) (Le Flèche et al., 1997). The outer surface protein $\mathrm{C}$ gene $(\operatorname{osp} C)$ was amplified by using primers ospC3 (5'-AAGTGCAGATATTAATGACTTTA-3') and ospC4 (5'-TTTTTTGGACTTTCTGCCACA-3') (Marti Ras et al., 1997).

The 348 bp fragment of flaB was digested with AluI (GibcoBRL, Life Technologies) as recommended by the manufacturer. Ten microlitres of the PCR product was digested with $4 \mathrm{U}$ CelII (Amersham Pharmacia Biotech) and DdeI (Gibco-BRL) for $1 \mathrm{~h}$ at $37^{\circ} \mathrm{C}$. The AluI, CelI I and DdeI digests were respectively separated in $3 \cdot 8,3 \cdot 0$ and $3 \cdot 8 \%$ $(\mathrm{w} / \mathrm{v})$ agarose gels (NuSieve GTG; FMC) containing $0.5 \mu \mathrm{g}$ ethidium bromide $\mathrm{ml}^{-1}$ in $1 \times$ TBE for $3,2.5$ and $3.5 \mathrm{~h}$ at a constant voltage of $100 \mathrm{~V}$. The molecular marker pBR322/HaeIII (Sigma-Aldrich) was used. Gels were photographed using the Eagle Eye II System (Stratagene) and a Polaroid GelCam. The RFLP patterns were measured and analysed by using EagleSight software (version 3.2) in the Eagle Eye II System as recommended by the manufacturer.

RFLP of $r r s$ was carried out with restriction enzyme $B f a \mathrm{I}$ (Le Flèche et al., 1997).

The PCR products were purified by QIAquick gel extraction kit (Qiagen). The DNA sequences of $f l a B$ and $r r s$ genes were determined by using an ABI Prism model 377 sequencer. Sequences were aligned manually and by using CLUSTAL $\mathrm{W}$ software (Thompson et al., 1994). Phylogenetic trees were
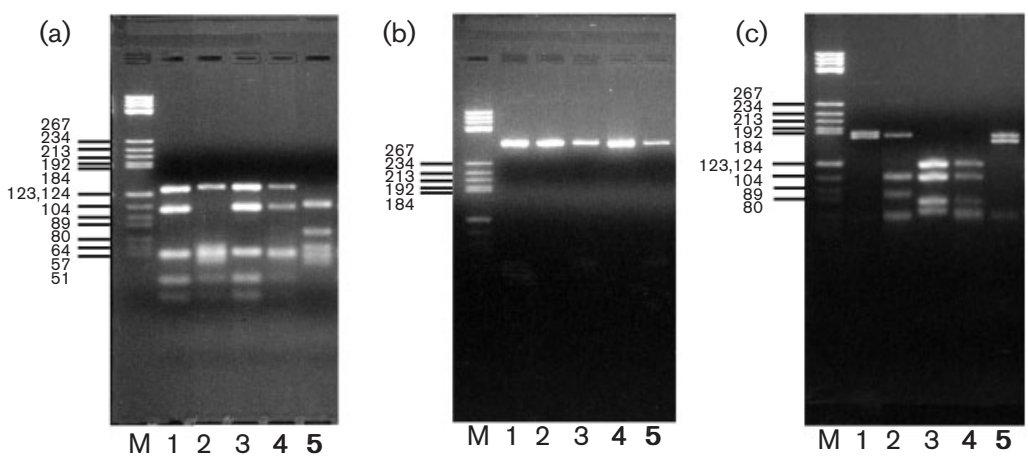

Fig. 1. Alul (a), Cell (b) and Ddel (c) restriction profiles of amplified fragments of flaB from TXW-1 and reference strains. Lanes: 1, B31 $1^{\top} ; 2,21038 ; 3$, DN127; 4, 25015; 5, TXW-1; M, molecular size markers. 
Table 1. Alul, Cell and Ddel restriction fragments of amplified partial flaB genes

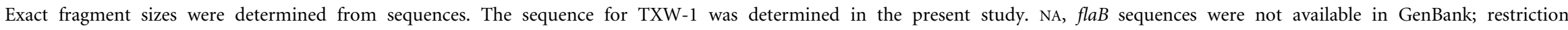
patterns were estimated based on RFLP patterns in gels.

\begin{tabular}{|c|c|c|c|c|c|c|c|c|}
\hline \multirow[t]{2}{*}{ Strain } & \multirow{2}{*}{$\begin{array}{l}\text { Amplicon } \\
\text { size (bp) }\end{array}$} & \multicolumn{2}{|r|}{ Alu I } & \multicolumn{2}{|r|}{ CelII } & \multicolumn{2}{|r|}{ DdeI } & \multirow{2}{*}{$\begin{array}{c}\text { Accession } \\
\text { no. }\end{array}$} \\
\hline & & Pattern & Fragment sizes (bp) & Pattern & Fragment sizes $(b p)$ & Pattern & Fragment sizes $(b p)$ & \\
\hline B. burgdorferi sensu stricto $\mathrm{B} 31^{\mathrm{T}}$ & 354 & A1 & $133,100,51,33,24,8,5$ & $\mathrm{~A} 2$ & No fragment & A3 & 180,174 & X16833 \\
\hline B. burgdorferi sensu stricto $\mathrm{SH}-2-82$ & 354 & A1 & $133,100,51,33,24,8,5$ & $\mathrm{~A} 2$ & No fragment & A3 & 180,174 & NA \\
\hline ‘B. bissettii’ DN127 & 354 & A1 & $133,100,51,33,24,8,5$ & A2 & No fragment & $\mathrm{C} 3$ & $117,102,72,63$ & D82857 \\
\hline 'B. bissettii’ 25015 & 354 & $\mathrm{~A} 1$ & $133,100,51,33,24,8,5$ & $\mathrm{~A} 2$ & No fragment & B3 & $117,102,63,45,27$ & $\mathrm{NA}$ \\
\hline 'B. andersonii' 21038 & 354 & D1 & $133,68,51,45,33,24$ & $\mathrm{~A} 2$ & No fragment & D3 & $174,100,80$ & D83763 \\
\hline Borrelia sp. TXW-1 & 348 & E1 & $103,69,54,48,43,12,8,6,5$ & $\mathrm{~A} 2$ & No fragment & F3 & $171,162,15$ & AF264901 \\
\hline B. garinii $20047^{\mathrm{T}}$ & 354 & $\mathrm{~F} 1$ & $133,102,63,36,15,5$ & A2 & No fragment & G3 & $171,102,72,9$ & D82846 \\
\hline B. afzelii $\mathrm{VS} 461^{\mathrm{T}}$ & 354 & G1 & $133,69,55,45,33,8,6,5$ & $\mathrm{~A} 2$ & No fragment & $\mathrm{H} 3$ & $180,132,42$ & D63365 \\
\hline B. valaisiana $\mathrm{VS} 116^{\mathrm{T}}$ & 354 & $\mathrm{H} 1$ & $133,124,51,33,8,5$ & $\mathrm{~A} 2$ & No fragment & $\mathrm{I} 3$ & $135,117,63,39$ & D82854 \\
\hline B. lusitaniae PotiB2 $^{\mathrm{T}}$ & 354 & I1 & $133,55,51,45,33,24,8,5$ & $\mathrm{~A} 2$ & No fragment & $\mathrm{A} 3$ & 180,174 & D82856 \\
\hline B. japonica $\mathrm{HO}_{14}^{\mathrm{T}}$ & 354 & $\mathrm{~J} 1$ & $133,69,63,51,33,5$ & $\mathrm{~A} 2$ & No fragment & $\mathrm{A} 3$ & 180,174 & D82852 \\
\hline B. tanukii Hk501 ${ }^{\mathrm{T}}$ & 354 & K1 & $133,69,55,51,33,8,5$ & $\mathrm{~A} 2$ & No fragment & $\mathrm{A} 3$ & 180,174 & D82847 \\
\hline B. turdi $\mathrm{Ya} 501^{\mathrm{T}}$ & 354 & L1 & $133,69,55,51,33,8,5$ & $\mathrm{~A} 2$ & No fragment & $\mathrm{A} 3$ & 180,174 & D82849 \\
\hline B. turicatae M2007 & 348 & M1 & $103,69,48,43,33,21,12,8,6,5$ & $\mathrm{~A} 2$ & No fragment & $\mathrm{J} 3$ & 186,162 & D86862 \\
\hline B. parkeri 6232 & 348 & N1 & $117,103,43,33,21,12,8,6,5$ & $\mathrm{~A} 2$ & No fragment & $\mathrm{J} 3$ & 186,162 & D82863 \\
\hline B. coriaceae $\operatorname{Co} 53^{\mathrm{T}}$ & 345 & $\mathrm{O} 1$ & $117,103,43,30,21,12,8,6,5$ & D2 & 171,174 & $\mathrm{~K} 3$ & 174,171 & D82864 \\
\hline B. hermsii HS1 & 348 & $\mathrm{P} 1$ & $153,103,43,12,12,8,6,6,5$ & A2 & No fragment & K3 & 177,171 & M86838 \\
\hline B. anserina ES-1 & 348 & Q1 & $103,69,55,48,42,9,9,8,5$ & A2 & No fragment & K3 & 177,171 & X75201 \\
\hline B. miyamotoi FR64b & 348 & $\mathrm{R} 1$ & $121,69,55,42,42,13,6$ & $\mathrm{~A} 2$ & No fragment & L3 & No fragment & D82860 \\
\hline 'B. lonestari' Texas & 330 & S1 & $117,87,55,36,16,13,6$ & $\mathrm{~A} 2$ & No fragment & L3 & No fragment & U26704 \\
\hline B. crocidurae ORI & 351 & $\mathrm{~T} 1$ & $93,90,45,42,36,12,10,6,6,6,5$ & $\mathrm{~A} 2$ & No fragment & L3 & No fragment & U28496 \\
\hline B. duttonii 406K & 351 & U1 & $103,69,55,45,36,12,8,6,6,6,5$ & $\mathrm{~A} 2$ & No fragment & L3 & No fragment & D82859 \\
\hline Borrelia sp. Spain & 348 & V1 & $124,109,51,45,8,6,5$ & $\mathrm{~A} 2$ & No fragment & L3 & No fragment & U28499 \\
\hline B. hispanica UESV/246 & 351 & W1 & $99,69,55,45,36,18,10,8,6,5$ & $\mathrm{~A} 2$ & No fragment & L3 & No fragment & U28498 \\
\hline
\end{tabular}




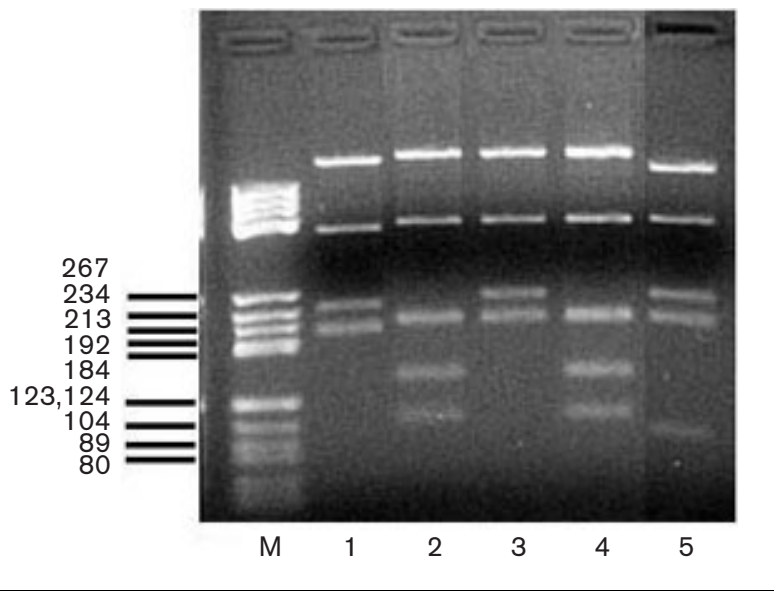

Fig. 2. Bfal restriction profiles of amplified fragments of $r$ s genes from TXW-1 and reference strains. Lanes: 1, B. burgdorferi sensu stricto $\mathrm{B} 1^{\top}$; 2 , ' $B$. bissettii' Al-1; 3, 'B. bissettii' FD-1; 4, ' $B$. andersonii' MOS-1b; 5, TXW-1; M, molecular size markers. constructed by neighbour-joining (Saitou \& Nei, 1987) using PAUP (Swofford, 2001).

RAPD-PCRs were performed by using previously published primers 1254, 1283 and AP13 (Wang et al., 1998). Reactions were performed as described previously (Wang et al., 1998) in a GeneAmpPCR System 9700 (PE Biosystems). The amplified DNA fragments were separated in $1 \%$ agarose $(\mathrm{w} / \mathrm{v})$ gels in $0.5 \times \mathrm{TBE}$ containing $0.5 \mu \mathrm{g}$ ethidium bromide $\mathrm{ml}^{-1}$. Gels were photographed using the Eagle Eye II System (Stratagene) and PCR-RAPD patterns were analysed as described above for RFLP.

Phenotypic characters of TXW-1 and reference strains were analysed by SDS-PAGE and Western blot. Briefly, reference strains and TXW-1 were incubated in BSK-H medium (Sigma-Aldrich) with $6 \%$ rabbit serum at $34{ }^{\circ} \mathrm{C}$ for 1-2 weeks until the cell density reached about $2 \times 10^{6}$ cells ml$^{-1}$. Ten millilitres of culture was washed with three cycles of washing with $0 \cdot 01 \mathrm{M} \mathrm{PBS}(\mathrm{pH} 7 \cdot 2)$ with $5 \mathrm{mM} \mathrm{MgCl}_{2}$ and centrifugation at 10000 r.p.m. (12 $\left.096 \mathrm{~g}\right)$

Table 2. Bfal restriction fragments of amplified partial rrs genes

Exact fragment sizes were determined from sequences. The sequence for TXW-1 was determined in the present study.

\begin{tabular}{|c|c|c|c|c|}
\hline Strain & $\begin{array}{l}\text { Amplicon } \\
\text { size (bp) }\end{array}$ & $\begin{array}{l}\text { BfaI RFLP } \\
\text { pattern }\end{array}$ & Fragment sizes (bp) & $\begin{array}{c}\text { Accession } \\
\text { no. }\end{array}$ \\
\hline B. burgdorferi sensu stricto $\mathrm{B} 31^{\mathrm{T}}$ & 1531 & A & $202,236,404,689$ & U03396 \\
\hline ‘B. bissettii’ DN127 & 1531 & A & $202,236,404,689$ & L40596 \\
\hline 'B. bissettii’ 25015 & 1531 & A & $202,236,404,689$ & AJ224138 \\
\hline 'B. andersonii' 21038 & 1531 & $\mathrm{~B}$ & $99,136,202,404,690$ & L46701 \\
\hline B. garinii $20047^{\mathrm{T}}$ & 1531 & $\mathrm{C}$ & $78,158,202,404,689$ & D67018 \\
\hline B. afzelii DK1 & 1531 & $\mathrm{D}$ & $136,202,504,689$ & X85190 \\
\hline B. japonica $\mathrm{HO} 14^{\mathrm{T}}$ & 1524 & G & $136,199,500,686$ & L40597 \\
\hline B. valaisiana $\mathrm{VS} 116^{\mathrm{T}}$ & 1531 & $\mathrm{E}$ & $58,78,202,504,689$ & X98232 \\
\hline B. lusitaniae PotiB2 ${ }^{\mathrm{T}}$ & 1531 & $\mathrm{~F}$ & $58,78,100,202,404,689$ & X98228 \\
\hline B. tanukii $\mathrm{Hk} 501^{\mathrm{T}}$ & 1531 & $\mathrm{~F}$ & $58,78,100,202,404,689$ & D67023 \\
\hline B. turdi $\mathrm{Ya}_{50} 1^{\mathrm{T}}$ & 1530 & $\mathrm{H}$ & $199,639,689$ & D67022 \\
\hline B. sinica $\mathrm{CMN} 2$ & 1537 & $\mathrm{H}$ & $202,647,688$ & AB022145 \\
\hline B. turicatae M2007 & 1531 & I & $88,202,236,403,602$ & U42299 \\
\hline B. parkeri 6232 & 1532 & I & $88,202,236,404,602$ & AF307100 \\
\hline Borrelia sp. TXW-1 & 1532 & I & $88,202,236,404,602$ & AF467976 \\
\hline B. hermsii HS1 & 1531 & I & $88,202,236,403,602$ & U42292 \\
\hline B. coriaceae $\mathrm{Co} 3^{\mathrm{T}}$ & 1531 & I & $88,202,236,403,602$ & U42286 \\
\hline B. miyamotoi $\mathrm{HT}_{3} 1^{\mathrm{T}}$ & 1532 & I & $88,202,236,404,602$ & D45192 \\
\hline Borrelia sp. FCB-1 & 1532 & I & $88,202,236,404,602$ & L37837 \\
\hline B. persica UESV/340 & 1532 & I & $88,202,236,403,603$ & U42297 \\
\hline Borrelia sp. LB-2001 & 1534 & I & $88,202,238,404,602$ & AY024345 \\
\hline B. anserina ES-1 & 1530 & $\mathrm{~J}$ & $15,88,202,236,388,601$ & U42284 \\
\hline 'B. lonestari' Texas & 1532 & $\mathrm{~J}$ & $15,88,202,236,389,602$ & U23211 \\
\hline B. crocidurae UESV/1096TEN & 1531 & $\mathrm{~J}$ & $15,88,202,236,388,602$ & U42302 \\
\hline B. duttonii $\mathrm{Ma}$ & 1532 & $\mathrm{~J}$ & $15,88,202,236,389,602$ & AF107366 \\
\hline B. hispanica UESV/246 & 1531 & $\mathrm{~J}$ & $15,88,202,236,388,602$ & U42294 \\
\hline Borrelia sp. Spain & 1531 & $\mathrm{~K}$ & $14,51,88,185,201,389,603$ & U28502 \\
\hline
\end{tabular}


for $10 \mathrm{~min}$. Washed pellets of the spirochaetes were then lysed by adding loading buffer. Twenty microlitres of cell lysate was heated at $100{ }^{\circ} \mathrm{C}$ for $10 \mathrm{~min}$ and then separated by SDS- $16 \cdot 5 \%$ PAGE. A low-molecular-mass marker (Sigma-Aldrich) was used to determine molecular masses. The gel was then stained with Coomassie brilliant blue R250. Western blotting was carried out by electrotransferring the proteins from the SDS-PAGE gel to a nitrocellulose membrane (Bio-Rad). The membrane was blocked by immersing in $5 \%$ dry milk for $1 \mathrm{~h}$ at room temperature. The whole membrane was reacted with mAb H9724 $(1: 100)$ for $1 \mathrm{~h}$ at room temperature and washed three times in Tris-buffered saline (TBS) with $0 \cdot 1 \%$ Tween 20 for $5 \mathrm{~min}$ each at room temperature. The membrane was then incubated in horseradish peroxidase-labelled antimouse second antibody (Kirkegarrd \& Perry Laboratories, Inc.) at $1: 1000$ dilution for $1 \mathrm{~h}$ at room temperature and subsequently washed three times in TBS with $0 \cdot 1 \%$ Tween 20 and once in distilled water, $5 \mathrm{~min}$ for each washing. The membrane was then incubated in TMB substrate solution at room temperature. The reaction was stopped by immersing the membrane in distilled water for 10-20 s when a suitable colour intensity was observed.

Measurement of DNA-DNA hybridization was performed by dot-blot analysis of samples with ${ }^{32} \mathrm{P}$-labelled probes. DNAs were extracted and purified from TXW-1 and reference strains by the method described previously (Lin et al., 2002). Aliquots of $2.5 \mu \mathrm{l}$ total genomic DNA purified from the various bacterial strains were spotted at four different concentrations $(25,5,1 \cdot 25$ and $0 \cdot 25$ ng DNA per dot) onto Hybond-XL nylon membrane (Amersham) and cross-linked with a Stratalinker 1800 UV cross-linker (Stratagene). Subsequently, membranes were prehybridized for $1 \mathrm{~h}$ at $60^{\circ} \mathrm{C}$ in ExpressHyb solution (Clontech) followed by $1 \mathrm{~h}$ hybridization at $60^{\circ} \mathrm{C}$ in ExpressHyb solution with $\left.{ }^{32} \mathrm{P}\right] \mathrm{dCTP}-$ labelled probe made from $100 \mathrm{ng}$ TXW-1 or $B$. parkeri genomic DNA by using an oligolabelling kit (Amersham). After hybridization, membranes were washed with $2 \times$ SSC, $0.05 \%$ SDS at room temperature for $40 \mathrm{~min}$ with five changes of wash solution. This was followed by two high-stringency washes at $50^{\circ} \mathrm{C}$ for 20 min each with $0 \cdot 1 \times$ SSC, $0 \cdot 1 \%$ SDS, according to the manufacturer's instructions (Clontech). Hybridization signal was detected by phosphorimager analysis using a Storm840 PhosphorImager system (Molecular Dynamics). Quantification of hybridization signal was performed by the NIH Image 1.62 software (http://rsb.info.nih.gov/nih-image/) and data are given as percentages relative to the homologous probe for four independent hybridizations (mean \pm SD).

B. burgdorferi sensu lato complex strains and relapsing fever borreliae consisted of $21 \mathrm{Alu}$ I RFLP types, two CelII RFLP types and 11 DdeI RFLP types. TXW-1 formed the

Table 3. Nucleotide similarity (\%) between flaB sequences from different genospecies of $B$. burgdorferi sensu lato complex and species of relapsing fever borreliae

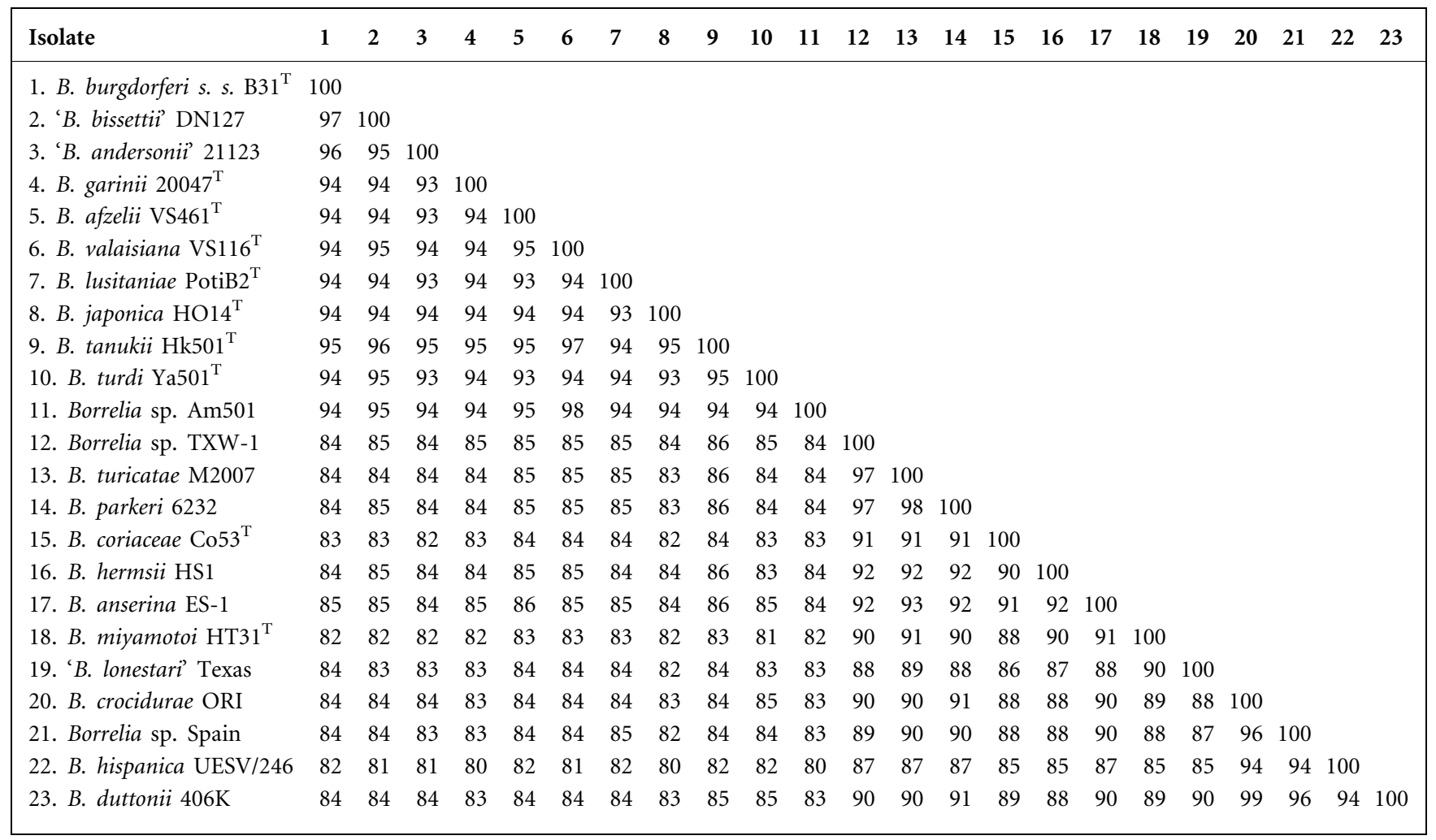

s. s., Sensu stricto. 
Table 4. Nucleotide similarity (\%) between $16 \mathrm{~S}$ rRNA gene sequences from different genospecies of $B$. burgdorferi sensu lato complex and species of relapsing fever borreliae

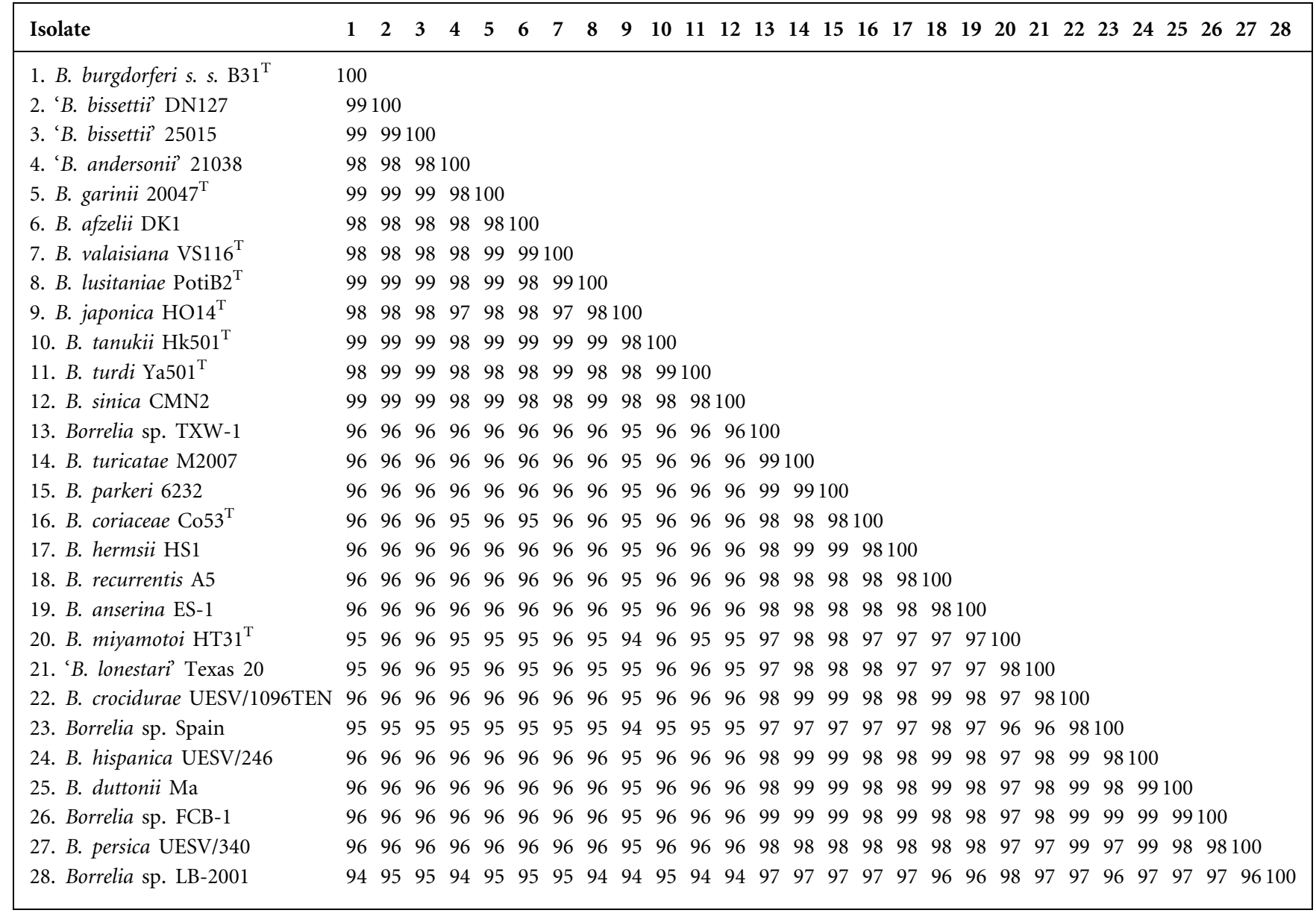

unique AluI RFLP type E1 and DdeI RFLP type F3 (Fig. 1; Table 1). The same strains contained 11 BfaI RFLP types; TXW-1 formed pattern I (Fig. 2; Table 2).

Nucleotide identities of flaB sequences from TXW-1 and strains of relapsing fever borreliae ranged from 87 to $97 \%$. The similarities of flaB nucleotide sequences among TXW-1 and B. turicatae (97\%) and B. parkeri (97\%) were less than that between $B$. turicatae and B. parkeri $(98 \%)$ (Table 3). Similar results were found for $r$ s nucleotide sequences. The rrs nucleotide sequence similarities among
TXW-1 and B. turicatae and B. parkeri were $99 \%$. Nucleotide identities among many species were $99 \%$ (Table 4 ).

Repeated RAPD analyses were performed with reference strains $\mathrm{B} 31^{\mathrm{T}}$, SH-2-82, DN127, 25015 and 21038 in order to assess the reproducibility of our RAPD fingerprinting procedure. We obtained similar DNA fingerprints for these strains in repeated RAPD analysis. No differences were seen between the RAPD patterns for $\mathrm{B} 31^{\mathrm{T}}$ at different passages (3 and 8) (data not shown). Based on the RAPD profiles in three individual amplifications with different primers, a

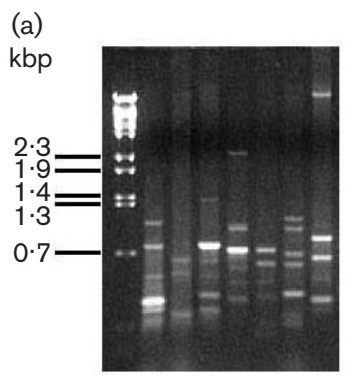

M1 2334567 (b)

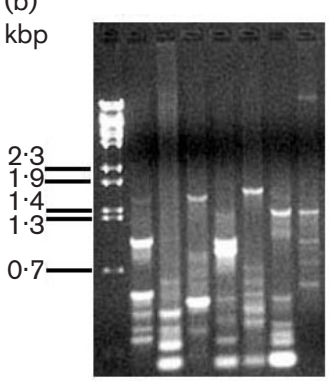

M1 2344567

(c)

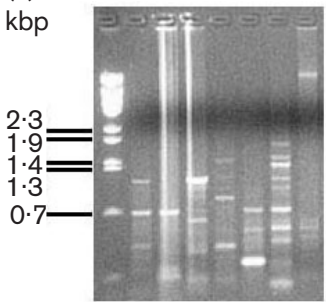

M1234567
Fig. 3. RAPD fingerprints of $T X W-1$ and reference strains from different genospecies obtained by using primers 1283 (a), AP13 (b) and 1254 (c). Lanes: 1, 25015; 2, SH2-82; 3, DN127; 4, 20047 ${ }^{\top} ; 5,21038 ; 6$, B31 ${ }^{\top} ;$ 7, TXW-1; M, lambda DNA/BstEll. Molecular sizes (in $\mathrm{kbp}$ ) are indicated on the left. 


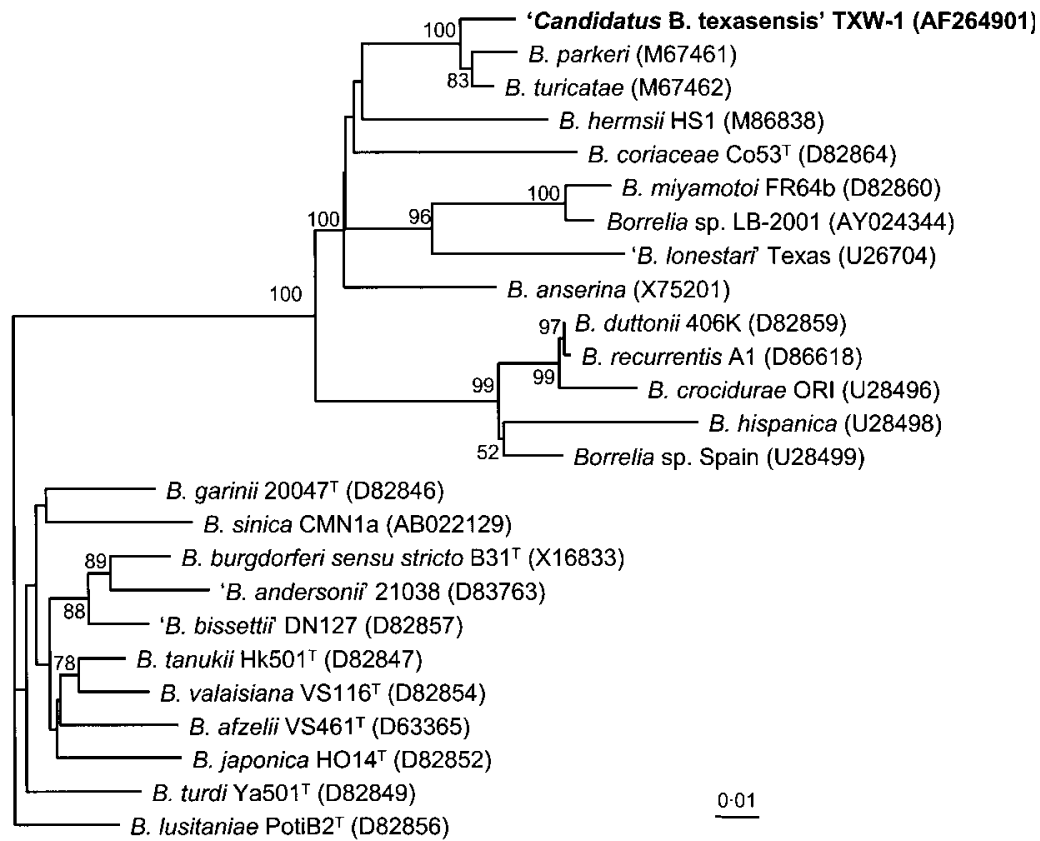

Fig. 4. Phylogenetic tree derived from fla $B$ nucleotide sequences of TXW-1 and reference strains of $B$. burgdorferi sensu lato and relapsing fever borreliae. The neighbourjoining tree was constructed with PAUP software and based on a comparison of 585-608 bp partial flaB sequences. The scale bar represents a calculated distance of 0.01 substitutions per site. Bootstrap confidence levels above $50 \%$ are indicated to left of each relevant cluster.

total of seven RAPD types were identified from the seven Borrelia strains that were compared (Fig. 3).

Based on sequence analysis of $f l a B$, TXW-1 forms a separate branch close to, but separate from, $B$. turicatae and $B$. parkeri. The genetic distance (indicated by branch length) between TXW-1 and B. turicatae $(0 \cdot 007)$ is greater than that between B. parkeri and B. turicatae (0.005) (Fig. 4). Similarly, the rrs phylogenetic tree revealed a separate branch for TXW-1 within the relapsing fever cluster. The genetic distance (indicated by branch length) between TXW-1 and B. turicatae $(0 \cdot 002)$ is greater than that between B. parkeri and B. turicatae (0.001) (Fig. 5).

The protein profiles of strains $\mathrm{B} 31^{\mathrm{T}}$ (B. burgdorferi sensu stricto), 20047 ${ }^{\mathrm{T}}$ (B. garinii), DN127 ('Borrelia bissettii), 25015 ('B. bissettii), 21038 ('Borrelia andersonii'), Co53 ${ }^{\mathrm{T}}$ (Borrelia coriaceae), HS1 (B. hermsii), RML (B. parkeri),

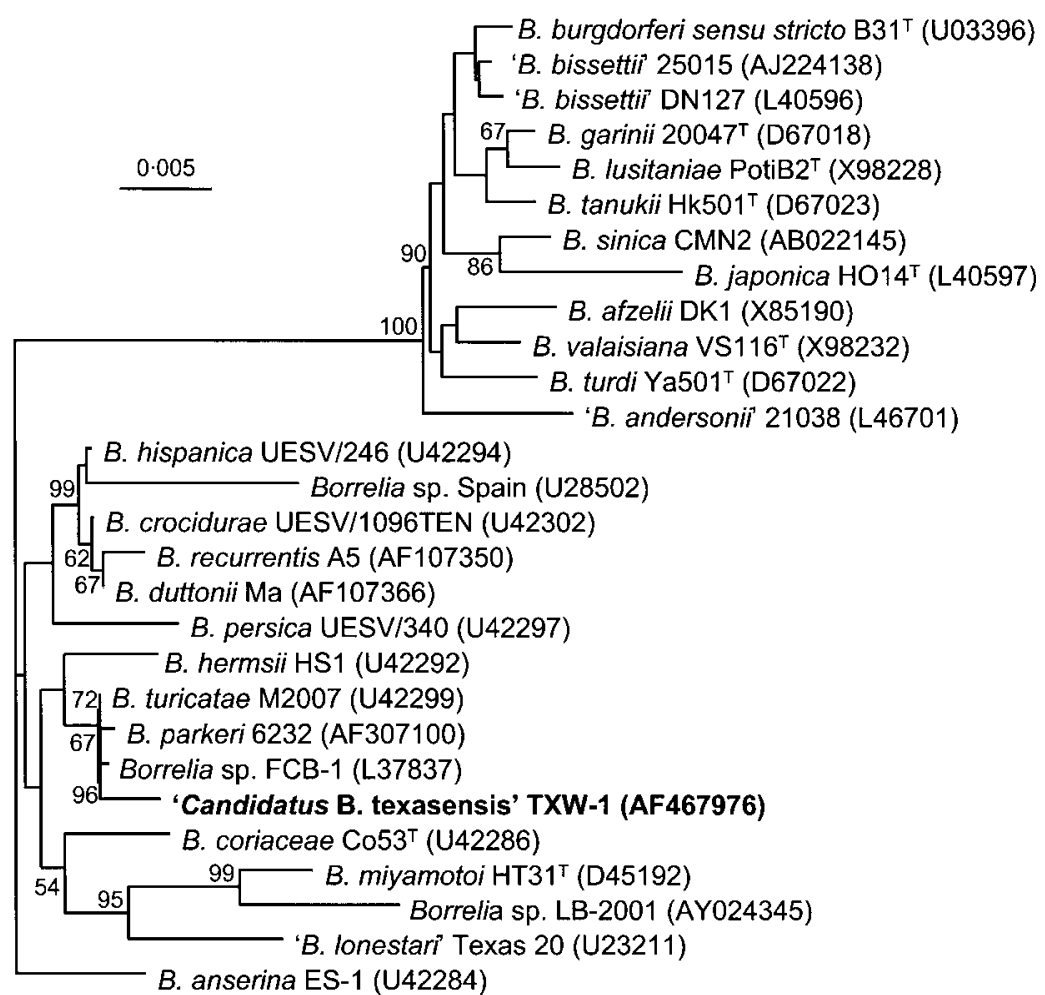

Fig. 5. Phylogenetic tree derived from rrs (16S rRNA gene) nucleotide sequences of TXW-1 and reference strains of $B$. burgdorferi sensu lato and relapsing fever borreliae. The neighbour-joining tree was based on a comparison of 1537 bp of nearly complete rrs genes. The scale bar represents 0.005 substitutions per site. See Fig. 4 legend for further details. 


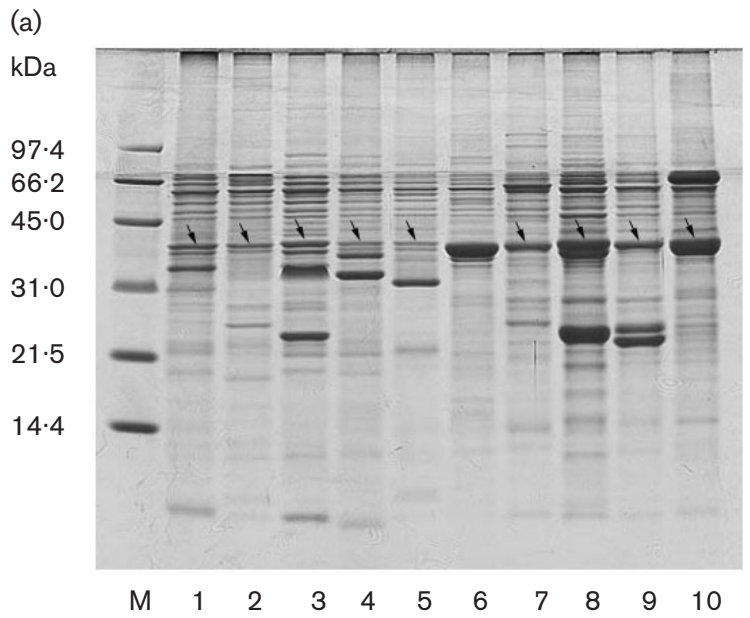

(b)

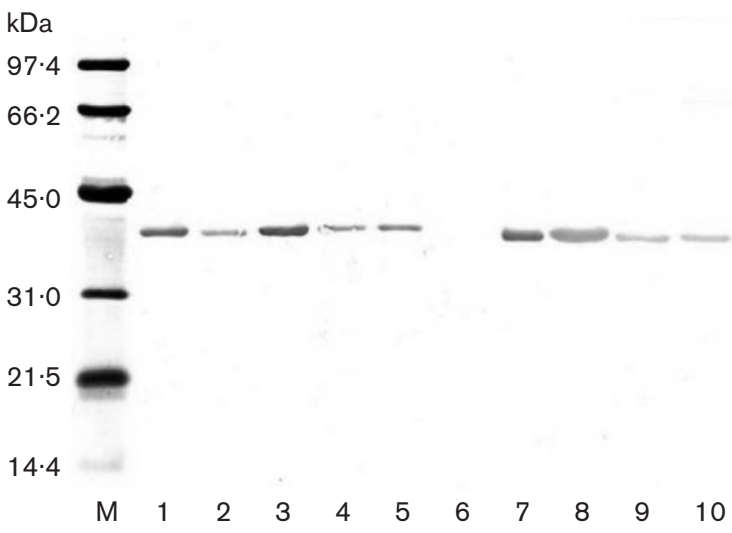

Fig. 6. (a) Coomassie brilliant blue-stained protein profiles of whole-cell lysates of TXW-1 and reference strains. Lanes: M, molecular mass markers; $1, B$. burgdorferi sensu stricto $B 31^{\top}$; 2, B. garinii 20047; 3, ' $B$. bissettii' DN127; 4, ' $B$. bissettii' 25015; 5, ' $B$. andersonii' 21038; 6, B. coriaceae Co53; 7, B. hermsii HS1; 8, B. parkeri RML; 9, B. turicatae OZ-1; 10, 'Candidatus B. texasensis' TXW-1. Arrows indicate positions of endoflagellar proteins reactive to mAb H9724. (b) Western blot with mAb H9724 against the flagellar protein. See (a) for further details.

OZ-1 (B. turicatae) and TXW-1 ('Candidatus B. texasensis') were different from one another (Fig. 6a). Major proteins including $31 \mathrm{kDa}$ OspA, $34 \mathrm{kDa}$ OspB and $22 \mathrm{kDa}$ OspC were clearly resolved for strain $\mathrm{B} 31^{\mathrm{T}}$ on a Coomassie brilliant blue-stained $16 \cdot 5 \%$ polyacrylamide gel (Fig. 6a). mAb H9724, which is specific for Borrelia flagellar protein, was used as a probe for Western blotting. Flagellar proteins of $41 \mathrm{kDa}$ were found in B. burgdorferi sensu lato strains $\mathrm{B} 31^{\mathrm{T}}, 20047^{\mathrm{T}}$, DN127, 25015 and 21038; however, a 38-kDa flagellar protein was found in TXW-1, similar to those found in relapsing fever borreliae HS1, RML and OZ-1 based on protein profiles and reactivity with $\mathrm{mAb} 9724$ (Fig. 6a, b).
DNA-DNA hybridization is a superior method for examining relationships between closely related taxa and for bacterial taxonomy (Stackebrandt \& Goebel, 1994). The ad hoc committee on reconciliation of approaches to bacterial systematics recommended that the level of DNA relatedness for separate species should be less than $70 \%$ (Wayne et al., 1987). DNA-DNA hybridization experiments revealed levels of DNA reassociation between TXW-1 and previously described relapsing fever borreliae of $38.64 \%$ (B. turicatae), $38 \cdot 40 \%$ (B. parkeri), $7 \cdot 39 \%$ (B. hermsii) and $18.30 \%$ (B. coriaceae). However, the level of DNA relatedness between $B$. parkeri and B. turicatae was $78 \cdot 78 \%$. Strain TXW-1 exhibited lower levels of DNA relatedness with $B$. parkeri and B. turicatae than that between B. parkeri and $B$. turicatae. Based on these results, TXW-1 is different from other described borreliae and therefore represents an undescribed species. Its closest relationship is to B. parkeri and B. turicatae.

It is not known whether the coyote is a natural host for TXW-1 and whether D. variabilis can maintain and transmit the spirochaete. The tick may have become infected during the larval or nymphal stages when feeding on unknown hosts. Thus, only limited data are available regarding the vector, vertebrate reservoir host and complete geographical distribution of TXW-1; nothing is known about its infectivity or pathogenicity. Nevertheless, our study provides the description of a novel spirochaete species among the relapsing fever borreliae. The results also enhance understanding of the diversity among borreliae and may be useful for future studies of the evolution of relapsing fever borreliae.

\section{Description of 'Candidatus Borrelia texasensis'}

'Candidatus Borrelia texasensis' (te.xas.en'sis. N.L. fem. adj. texasensis of Texas, USA, where the organism was isolated).

Cells are actively motile with reversal, rotational and translational movements. Structurally, they consist of an outer membrane that surrounds a protoplasmic cylinder complex and flagella. They have six to ten flexible helical coils and are $0 \cdot 21-0 \cdot 24 \mu \mathrm{m}$ wide and $9 \cdot 41-11 \cdot 23 \mu \mathrm{m}$ long. The wavelengths are $1 \cdot 12-1.53 \mu \mathrm{m}$ (a scanning electron micrograph of TXW-1 is available as supplementary material in IJSEM Online). Cells have tapered ends. Microaerophilic spirochaete that can be cultured in BSK$\mathrm{H}$ medium at $34^{\circ} \mathrm{C}$. Gram-negative and stains well with Giemsa's stain. Stained cells are visible by bright-field microscopy but, to observe unstained cells, dark-field microscopy is required. Pathogenicity and infectivity remain to be determined.

\section{Acknowledgements}

Special thanks to G. Teltow (Texas Department of Health) for sending us the Dermacentor variabilis tick from which we isolated the TXW-1 spirochaete strain. We thank Professor Dr Peter Kämpfer, Editor of IJSEM, and two reviewers for constructive suggestions to improve the 
manuscript. This research was supported in part by grant R37 AI-24899 from the National Institutes of Health. The opinions expressed are the responsibility of the authors and do not necessarily represent the official views of the NIH.

\section{References}

Anderson, J. F. \& Magnarelli, L. A. (1993). Natural history of Borrelia burgdorferi in vectors and vertebrate hosts. In Ecology and Environmental Management of Lyme Disease, pp. 11-24. Edited by H. S. Ginsberg. New Brunswick, NJ: Rutgers University Press.

Barbour, A. G. \& Hayes, S. F. (1986). Biology of Borrelia species. Microbiol Rev 50, 381-400.

Barbour, A. G., Maupin, G. O., Teltow, G. J., Carter, C. J. \& Piesman, J. (1996). Identification of an uncultivable Borrelia species in the hard tick Amblyomma americanum: possible agent of a Lyme disease-like illness. J Infect Dis 173, 403-409.

Cutler, S. J., Jones, S. E., Wright, D. J. M. \& Zhang, H. (2000). Cultivation of East African relapsing fever Borrelia and review of preceding events. J Spirochetal Tick-borne Dis 7, 52-58.

Fraenkel, C. J., Garpmo, U. \& Berglund, J. (2002). Determination of novel Borrelia genospecies in Swedish Ixodes ricinus ticks. J Clin Microbiol 40, 3308-3312.

Fukunaga, M. \& Koreki, Y. (1995). The flagellin gene of Borrelia miyamotoi sp. nov. and its phylogenetic relationship among Borrelia species. FEMS Microbiol Lett 134, 255-258.

Kelly, R. T. (1971). Cultivation of Borrelia hermsi. Science 173, 443-444.

Kelly, R. T. (1976). Cultivation and physiology of relapsing fever borreliae. In The Biology of Parasitic Spirochetes, pp. 87-94. Edited by R. C. Johnson. New York: Academic Press.

Kelly, R. T. (1984). Genus IV. Borrelia Swellengrebel 1907, $582^{\mathrm{AL}}$. In Bergey's Manual of Systematic Bacteriology, vol. 1, pp. 57-62. Edited by N. R. Krieg \& J. G. Holt. Baltimore: Williams \& Wilkins.

Le Flèche, A., Postic, D., Girardet, K., Péter, O. \& Baranton, G. (1997). Characterization of Borrelia lusitaniae sp. nov. by $16 \mathrm{~S}$ ribosomal DNA sequence analysis. Int J Syst Bacteriol 47, 921-925.

Lin, T., Oliver, J. H., Jr \& Gao, L. (2002). Genetic diversity of the outer surface protein $\mathrm{C}$ gene of southern Borrelia isolates and its possible epidemiological, clinical, and pathogenetic implications. J Clin Microbiol 40, 2572-2583.

Marti Ras, N., Postic, D., Foretz, M. \& Baranton, G. (1997). Borrelia burgdorferi sensu stricto, a bacterial species "made in the U.S.A."? Int J Syst Bacteriol 47, 1112-1117.

Saitou, N. \& Nei, M. (1987). The neighbor-joining method: a new method for reconstructing phylogenetic trees. Mol Biol Evol 4, 406-425.

Schwan, T. G. \& Piesman, J. (2002). Vector interactions and molecular adaptations of Lyme disease and relapsing fever spirochetes associated with transmission by ticks. Emerg Infect Dis 8, 115-121.

Scoles, G. A., Papero, M., Beati, L. \& Fish, D. (2001). A relapsing fever group spirochete transmitted by Ixodes scapularis ticks. Vector Borne Zoonotic Dis 1, 21-34.

Stackebrandt, E. \& Goebel, B. M. (1994). Taxonomic note: a place for DNA-DNA reassociation and 16S rRNA sequence analysis in the present species definition in bacteriology. Int J Syst Bacteriol 44, 846-849.

Swofford, D. L. (2001). PAUP - Phylogenetic Analysis Using Parsimony and other methods, 4th edn. Sunderland, MA: Sinauer Associates.

Thompson, J. D., Higgins, D. G. \& Gibson, T. J. (1994). CLUSTAL W: improving the sensitivity of progressive multiple sequence alignment through sequence weighting, position-specific gap penalties and weight matrix choice. Nucleic Acids Res 22, 4673-4680.

Varela, A. S., Luttrell, M. P., Howerth, E. W., Moore, V. A., Davidson, W. R., Stallknecht, D. E. \& Little, S. E. (2004). First culture isolation of Borrelia lonestari, putative agent of southern tick-associated rash illness. J Clin Microbiol 42, 1163-1169.

Wang, G., van Dam, A. P., Spanjaard, L. \& Dankert, J. (1998). Molecular typing of Borrelia burgdorferi sensu lato by randomly amplified polymorphic DNA fingerprinting analysis. J Clin Microbiol 36, 768-776.

Wayne, L. G., Brenner, D. J., Colwell, R. R. \& 9 other authors (1987). Report of the ad hoc committee on reconciliation of approaches to bacterial systematics. Int J Syst Bacteriol 37, 370-377.

Zingg, B. C., Brown, R. N., Lane, R. S. \& LeFebvre, R. B. (1993). Genetic diversity among Borrelia burgdorferi isolates from wood rats and kangaroo rats in California. J Clin Microbiol 31, 3109-3114. 